\title{
Optimal insemination and replacement decisions to minimize the cost of pathogen-specific clinical mastitis in dairy cows
}

\author{
E. Cha, ${ }^{* 1,2}$ A. R. Kristensen,† J. A. Hertl, ${ }^{*}$ Y. H. Schukken, ${ }^{*}$ L. W. Tauer, $¥$ F. L. Welcome,§ and Y. T. Gröhn ${ }^{\star}$ \\ ${ }^{*}$ Section of Epidemiology, Department of Population Medicine and Diagnostic Sciences, College of Veterinary Medicine, Cornell University, Ithaca, \\ NY 14853 \\ HHERD-Centre for Herd-Oriented Education, Research and Development, Department of Large Animal Sciences, University of Copenhagen, \\ Grønnegårdsvej 2, DK-1870 Frederiksberg C, Copenhagen, Denmark \\ $\ddagger$ Charles H. Dyson School of Applied Economics and Management, College of Agriculture and Life Sciences, and \\ $\S$ Quality Milk Production Services, Department of Population Medicine and Diagnostic Sciences, College of Veterinary Medicine, Cornell \\ University, Ithaca, NY 14853
}

\begin{abstract}
Mastitis is a serious production-limiting disease, with effects on milk yield, milk quality, and conception rate, and an increase in the risk of mortality and culling. The objective of this study was 2-fold: (1) to develop an economic optimization model that incorporates all the different types of pathogens that cause clinical mastitis (CM) categorized into 8 classes of culture results, and account for whether the CM was a first, second, or third case in the current lactation and whether the cow had a previous case or cases of $\mathrm{CM}$ in the preceding lactation; and (2) to develop this decision model to be versatile enough to add additional pathogens, diseases, or other cow characteristics as more information becomes available without significant alterations to the basic structure of the model. The model provides economically optimal decisions depending on the individual characteristics of the cow and the specific pathogen causing CM. The net returns for the basic herd scenario (with all CM included) were $\$ 507 /$ cow per year, where the incidence of CM (cases per 100 cow-years) was 35.6, of which $91.8 \%$ of cases were recommended for treatment under an optimal replacement policy. The cost per case of CM was $\$ 216.11$. The CM cases comprised (incidences, \%) Staphylococcus spp. (1.6), Staphylococcus aureus (1.8), Streptococcus spp. (6.9), Escherichia coli (8.1), Klebsiella spp. (2.2), other treated cases (e.g., Pseudomonas; 1.1), other not treated cases (e.g., Trueperella pyogenes; 1.2), and negative culture cases (12.7). The average cost per case, even under optimal decisions, was greatest for Klebsiella spp. (\$477), followed by E. coli $(\$ 361)$, other treated cases $(\$ 297)$, and other not treated cases $(\$ 280)$. This was followed by
\end{abstract}

Received May 26, 2013.

Accepted December 31, 2013.

${ }^{1}$ Corresponding author: elvacha@gmail.com

${ }^{2}$ Current address: Novartis Pharmaceuticals Corporation, One Health Plaza, East Hanover, NJ 07936. the gram-positive pathogens; among these, the greatest cost per case was due to Staph. aureus (\$266), followed by Streptococcus spp. (\$174) and Staphylococcus spp. (\$135); negative culture had the lowest cost (\$115). The model recommended treatment for most $\mathrm{CM}$ cases (>85\%); the range was $86.2 \%$ (Klebsiella spp.) to $98.5 \%$ (Staphylococcus spp.). In general, the optimal recommended time for replacement was up to 5 mo earlier for cows with CM compared with cows without CM. Furthermore, although the parameter estimates implemented in this model are applicable to the dairy farms in this study, the parameters may be altered to be specific to other dairy farms. Cow rankings and values based on disease status, pregnancy status, and milk production can be extracted; these provide guidance when determining which cows to keep or cull.

Key words: mastitis, pathogen, cost, rank, dynamic programming

\section{INTRODUCTION}

Intensive dairy farming is characterized by maximizing revenue through the sale of consumable milk and beef. Mastitis is a serious production-limiting disease in this industry, having effects on milk yield (Gröhn et al., 2004; Bar, 2007; Schukken et al., 2009), milk quality (Barbano et al., 2006), conception rate (Hertl et al., 2010), and the risk of mortality and culling (Bar et al., 2008a; Hertl et al., 2011; Cha et al., 2013). Furthermore, treatment of mastitis-infected cows may be necessary depending on the pathogen causing mastitis, leading to a loss of saleable milk during and following treatment according to required withholding periods.

We developed a dynamic programming model to determine the optimal economic decisions for mastitis control. One of the basic elements of dynamic programming is a sequential approach to decision making, which aligns well with sequential decisions in animal production, including replacement of animals, where, at regu- 
lar time intervals, management decisions are made such as whether an animal should be inseminated, replaced, or kept for another period. Optimal replacement models can be used to provide dairy farmers guidance on what actions to take with their animals (Nielsen et al., 2010; Demeter et al., 2011). The advantage of these models is that they can assimilate large amounts of information on health status, age of the cow, current milk production, and so on, to determine the optimal action to be taken (Bar et al., 2008a).

A useful animal replacement model needs to include the information necessary in identifying the optimal decision. Given that the goal of intensive dairy farming is typically to maximize revenue, one optimality criterion would logically be the maximization of net returns. Dairy cattle replacement models maximizing return or minimizing cost have been developed (De Vries, 2006; Nielsen et al., 2010; Demeter et al., 2011), with inclusion of disease information (Houben et al., 1994; Bar et al., 2008a; Cha et al., 2011), but these previously developed models were not as comprehensive as the currently developed model because of the recent availability of increasingly precise data on clinical mastitis (CM).

A predecessor to our model was published by Bar et al. (2008a), who developed an animal replacement model that incorporated information on generic $\mathrm{CM}$ and that extended and built upon the assumptions of the optimal replacement model developed by Houben et al. (1994) and earlier models using asset replacement principles (Perrin, 1972). Because large differences exist between the pathogens that cause CM in the pathobiology of infection (Schukken et al., 2011), models accounting for the difference between these pathogens would be preferable over a model that only used CM as an undifferentiated generic event. For that reason, Cha et al. (2011) modified the original model by Bar et al. (2008a) to study 3 groupings of CM (gram-positive, gram-negative, and other). Although the use of these 3 groupings provided a more realistic model, in many cases more complete information is available, and a next generation of decision models that fully take advantage of the knowledge of the causal organism would be preferable.

In the current study, we therefore developed an extended model for several reasons:

1. The previous model did not separate $\mathrm{CM}$ into different causal pathogens. Depending on the pathogen involved, further differentiation into a first, second, or third case in the lactation may be useful for optimal decision making. In all these classifications, the risk of repeated CM, milk loss, reduced rate of conception, mortality risk (Cha et al., 2013), and treatment cost will differ between classes. The importance of pathogen-specific information is especially relevant in situations where the profile of a cow results in a borderline decision (Østerås et al., 1999). Further, inclusion of the most detailed level of information (i.e., pathogen-specific CM) most accurately incorporates the dynamics between pathogens on farm. Previous pooling of pathogens into groups (at the generic and gramspecific levels) ignores these real-life dynamics.

2. Detailed information was not previously available, but we now have additional information relating to the risk of CM by case number, carryover from the previous lactation, and causal pathogen. Further, we have information on milk loss by case number and pathogen, conception rate, mortality risk (Cha et al., 2013), and treatment cost by pathogen.

3. The previous model did not have the versatility to include additional pathogens or additional diseases easily; the new model affords the versatility to expand the model further.

4. By allowing more than one event to occur as a cow transitions from one month to another, modeling concurrent transitions in $\mathrm{CM}$ status, pregnancy status, and milk yield is possible.

The objectives of this study were (1) to develop and solve an economic optimization model that incorporates the different types of pathogens that cause CM categorized into 8 culture result classes, as well as account for whether the CM was a first, second, or third case in the current lactation and whether the cow had one or more previous cases of $\mathrm{CM}$ in the preceding lactation; (2) to determine optimal management decisions by minimizing the cost of pathogen-specific CM; (3) to estimate the cost of CM by pathogen; and (4) to develop the model such that it is easily expandable and sufficiently versatile to allow the addition of more pathogens, diseases, or other factors without significant alterations to the basic structure of the model.

In addition, the model was developed to have a structure that could be easily expanded for inclusion of more diseases as information becomes available. The model developed by Bar et al. (2008a) was the first generic CM model providing optimal management decisions for CM cows, but unfortunately had a structure that was not amenable to the addition of more detailed mastitis information. The current model, however, was developed in such a way that significant additions and changes could be made to study pathogen-specific CM. 


\section{MATERIALS AND METHODS}

In the current study, the basic hierarchical structure of the Bar et al. (2008a) model was retained; that is, 5 permanent (i.e., genetic) milk yield levels, 5 temporary (i.e., daily) milk yield levels, and 20 mo per lactation. The state space, however, was completely reprogrammed, as were the transition probabilities and economic values. Bearing in mind that this model may be used in the future to add additional pathogens, the model was built to have a more versatile structure than the Bar et al. (2008a) model. Instead of hard coding the CM states, we created a variable to represent the number of CM pathogens included. By simply changing the number allocated to this variable, the number of CM states would automatically be updated in the model. Second, we created a disease class, where functions were created; for example, asking for risk of CM by lactation and month in lactation. These functions were used in programming the transition probabilities. The purpose of creating these functions was so that the transition probabilities would not be hard coded as had been previously done, making it easier to add additional CM pathogens or other diseases to the economic model. The same approach was followed when setting the economic values in the program. Last, as more states were added, it became increasingly difficult for optimization to be performed as the model became prohibitively large; to save space, labels (i.e., describing state of the cow) were reused and the most pertinent biological parameters in determining the economically optimal CM decisions were implemented, which put a necessary cap on the size of the state space designed.

Because of the increase in the number of pathogens studied, the number of simulations that were run increased substantially (i.e., instead of only identifying net returns/year for generic CM, this needed to be performed for 8 different pathogens). To maximize efficiency, a batch execution class was created, such that simulations could be run one by one automatically, instead of needing to be manually run at the computer as was the case previously.

\section{Categorization of CM}

We classified CM into 8 bacterial pathogen categories: (1) Staphylococcus spp., (2) Staphylococcus aureus, (3) Streptococcus spp., including Streptococcus uberis and Streptococcus dysgalactiae, (4) Escherichia coli, (5) Klebsiella spp., (6) other treated (these included Enterobacter, Enterococcus, Citrobacter, Serratia, Pasteurella, Corynebacterium, Pseudomonas, Proteus, Corynebacterium bovis, gram-positive bacilli, and gram-negative bacilli), (7) other not treated (these included Trueperella pyogenes, Mycoplasma, Prototheca, and yeast), and (8) negative culture: contamination $(>2$ bacterial species on the culture plate) and no significant organisms. The latter, no significant organisms, was defined as a plate on which it was possible to determine that no bacterial growth of either Staph. aureus or Strep. agalactiae but that contained more than 2 different species. The cases in category 8, like all other categories, did, however, exhibit clinical signs of mastitis.

\section{Replacements and Inseminations Optimization and Simulation Model}

Software. The model was built using the multilevel hierarchic Markov process (MLHMP) software as the application program (Kristensen, 2003). We made significant additions and changes to the structure of an existing optimization and simulation model first developed by Bar et al. (2008a) to study the cost of generic $\mathrm{CM}$ in dairy cows and then modified to study 3 different types of lameness in dairy cows (Cha et al., 2010). In the current model, we included a pathogen class, where parameters specific to each pathogen can be changed in the user graphical interface, allowing for the study of the effect of different parameters and prices on the cost of $\mathrm{CM}$ and optimal replacement decisions.

The Model. The model was constructed as a 3-level hierarchic Markov process comprising the first (parent) level, which contained state variables of permanent traits throughout the cow's life span, the second level divided into stages representing 1 whole lactation, and the third level divided into stages of 1 mo during lactation. The lactation number and stage of lactation are known properties from the hierarchical model structure; therefore, these were not included directly as state variables. The possible actions in a given month of lactation that could occur at the final level were (1) replace the cow with a recently calved, first-lactation animal, (2) keep the cow for another month without insemination and treat her if she has CM, or (3) keep the cow for another month and inseminate her and treat her if she has CM. An alternative possible decision for CM cows was to keep these cows on the farm without treatment; however, because we did not have access to detailed information on such cases, we did not have the parameter values necessary to model this action. Also, withholding treatment to known affected animals is not ethically acceptable. Figure 1 is a schematic representation of the model used in the current study on CM. At the first level, 5 permanent milk yield categories were modeled as $-5,-2.5,0,+2.5$, and $+5(\mathrm{~kg})$ from the mean level of milk production per day; these permanent milk yield categories represented the cow's genetic potential. At the next (second) level, 5 possible whole-lactation 


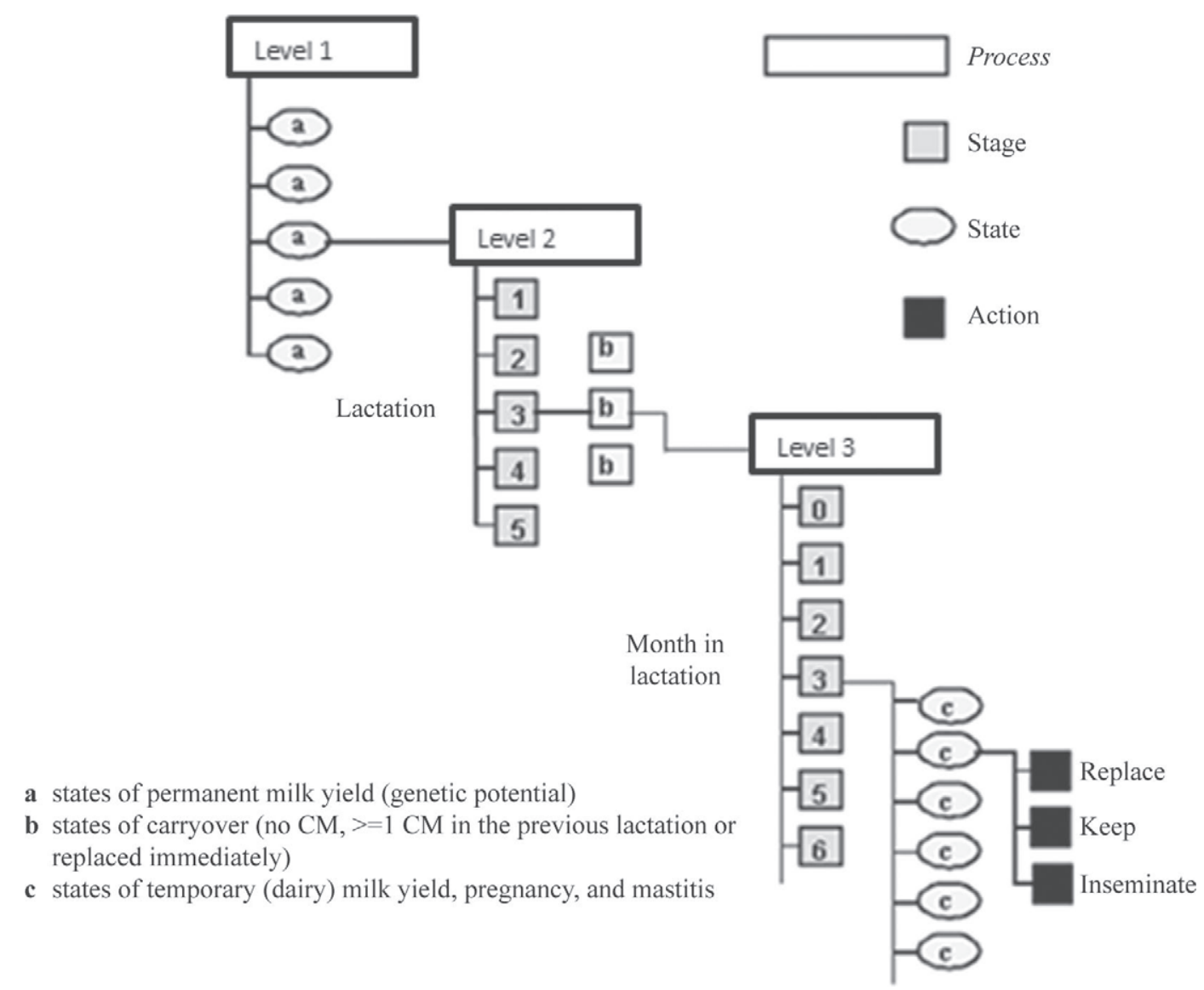

Figure 1. Schematic diagram of the dynamic program structure. $\mathrm{CM}=$ clinical mastitis.

stages were modeled. We also included a carryover state from lactation 2 onward; that is, whether the cow had a case of $\mathrm{CM}$ in the preceding lactation (yes/no). At the third level, 20 lactation stages (months) were modeled. The first month was divided into the first $3 \mathrm{~d}$ since calving and then the remainder of the month. In each stage, the cow was described by one level within each of the following states: 5 temporary (i.e., daily) milk yield levels, 9 pregnancy states $[0=$ open, $1-7=1-7$ mo pregnant and milking, and $8=$ last 2 mo of pregnancy and dry (not milking)], 1 involuntarily culled state, and 9 CM states. The CM states were defined as follows: 0 $=$ no CM, $1=$ Staphylococcus spp., $2=$ Staph. aureus, $3=$ Streptococcus spp., $4=$ E. coli, $5=$ Klebsiella spp., $6=$ other treated, $7=$ other not treated, and $8=$ negative culture. We also introduced a history variable, $\mathrm{H}$, which ranged from 0 to 3 , where $\mathrm{H}$ indicates the case number if the cow has CM. For example, $\mathrm{CM}=2$ and $\mathrm{H}=1$ means the cow has a first case of Staph. aureus; $\mathrm{CM}=0, \mathrm{H}=0$ indicates that the cow has never had CM since calving; $\mathrm{H}=3$ means that this is the cow's third or greater case in the current lactation. We also introduced a variable to indicate the number of months that have passed since the previous case of CM (if the cow had a previous CM case), termed PM. This variable ranged from 0 to 3 , where 3 indicates months $\geq 3$. The resulting total state space had 2,095,425 combinations.

This model assumed that replacement heifers were readily available, thus maintaining a constant herd size. We also assumed that decisions were made at the end of each stage and the effects of the disease occurred in the following stage, depending on the decision taken. Also, when a cow transitioned from one state to another, we allowed for more than one change in her state at any one point in time. For example, a cow could conceive and have a case of CM in the same month.

The objective function maximized was the discounting criterion (Kristensen, 2003), which maximizes the net present value of the cow using a yearly interest rate of $8 \%$ (De Vries, 2006; Bar et al., 2008a).

Optimization Technique. By combining the advantages of the 2 types of iteration methods used to solve the Markov process (namely, value iteration and policy iteration), a new notion of a hierarchic Markov process was implemented by Kristensen $(1988,1991)$ and later generalized by Kristensen and Jørgensen (2000). The 
notion forms the basis of solving our dynamic program. This solution approach allows us to obtain solutions to large state-space problems as described below.

Value iteration was performed to identify the decision that maximized the total expected discounted rewards when the process started from state $i$ and continued for $n$ stages before ending. Policy iteration involves choosing an arbitrary set of decision rules for each state at each stage and solving a set of simultaneous linear equations describing the expected future rewards of a process starting from state $i$ and running over an infinite number of stages until the same optimal decision is reached (Kristensen et al., 2010).

Kristensen (1988, 1991) combined the benefits of both policy and value iteration by applying value iteration to the subprocesses and using these results in the final step of the policy iteration method of the main process. Our model is structured in such a way that a cow can be replaced until time infinity, hence at the first (parent) level, we have an infinite time horizon. At the subprocess (second and third) levels, however, we have a finite time horizon (i.e., the lifespan of a specific cow). Hence, in our model, at the first level, we used policy iteration, and at the second and third levels, value iteration (Figure 1).

\section{Model Parameters}

Model parameters were obtained from analyses of data from 5 dairy herds in New York State. These 5 herds were followed for approximately 7 to 8 yr (2003 or 2004 to 2011), and provided data on a total of 50,166 lactations from 23,409 cows. Model parameters specific to the 8 different pathogens causing $\mathrm{CM}$ are given in Tables 1, 2, and 3. These were relatively large dairy farms using freestall housing, TMR feeding, and parlor milking. None were organically managed dairy herds. Papers discussing the data collection and analysis include Barlow et al. (2013), Cha et al. (2013), Lago et al. (2011), and Schukken et al. (2011, 2013).

The monthly involuntary culling risks for lactations 1 through 5 for healthy cows were $0.003,0.005,0.008$, 0.01 , and 0.01 , respectively (pathogen-specific involuntary culling risks are in Table 3 ). The risk of mortality at time of calving was set at $2 \%$, accounting for mortality in the postcalving stage; that is, the first $3 \mathrm{~d}$ after calving (Bar et al., 2008a). Treatment costs and average daily milk loss $(\mathrm{kg})$ since onset of pathogen specific CM by parity, case, and months elapsed $(1,2,3+)$ are presented in Table 3. The references used in calculating treatment costs are listed in the table footnotes. These treatment costs included costs for veterinary care, including antibiotic treatments and systemic treatment in a proportion of cases that are sick, and the cost of culturing milk samples (the latter was accounted for in calculating net returns). Pathogen-specific treatment protocols were developed based on published studies on treatment efficacy (Lago et al., 2011; Schukken et al., 2011, 2013; Barlow et al., 2013). Systemic illness was expected to occur in $10 \%$ of all clinical cases, with the exception of Staphylococcus spp. and Staph. aureus, where no systemic illness was expected, and of E. coli and Klebsiella spp., where $20 \%$ of cases were expected to have systemic illness.

Cost of Staphylococcus spp. treatment comprised antibiotics in $50 \%$ of cases; that is, use of label treatment with cephapirin (Today, Boehringer Ingelheim, St. Joseph, MO) as the treatment of choice (2 tubes of treatment in 12 -h period, $\$ 2.50 \times 2=\$ 5.00 ; 50 \%$ of cows $=\$ 2.50)$ and labor $(\$ 10)$, for a total of $\$ 12.50$. The duration of discarded milk due to antibiotics was $5 \mathrm{~d}$ (24-h duration of Today treatment plus 96-h withdrawal period beginning after the final treatment) and applied to 50\% of Staphylococcus spp. cases.

Cost of Staph. aureus treatment comprised antibiotics; that is, use of pirlimycin (Pirsue, Zoetis, Florham Park, NJ) for $8 \mathrm{~d}$ as the treatment of choice $(\$ 4.50 \times$ $8=\$ 36)$ and labor $(\$ 10)$, for a total of $\$ 46$. The duration of discarded milk due to antibiotics was $9.5 \mathrm{~d}$ (8 $\mathrm{d}$ of pirlimycin treatment plus 36 -h withdrawal period beginning after final treatment).

Cost of Streptococcus spp. treatment comprised label treatment of antibiotics; that is, use of cephapirin (Today, Boehringer Ingelheim) as the treatment of choice (2 tubes of treatment in 12 -h period, i.e., $\$ 2.60 \times 2$ $=\$ 5.20), 10 \%$ of cows receiving systemic antibiotics and antiinflammatory drugs (ceftiofur, Naxcel, Zoetis, 2 doses $=\$ 5.00 \times 2=\$ 10.00+$ flunixin 2 treatments $\times$ $\$ 3=\$ 6 ; 10 \%$ of cows $=\$ 1.60)$ and fluids intravenously per os $(2.5 \mathrm{~L} \times \$ 7 / \mathrm{L}=\$ 17.5 ; 10 \%$ of cows $=\$ 1.75)$ and labor $(\$ 20)$, for a total of $\$ 28.55$. The duration of discarded milk due to antibiotics and antiinflammatory drugs was $5 \mathrm{~d}$ (24-h duration of Today treatment plus 96 -h withdrawal period beginning after final treatment).

Cost of E. coli and Klebsiella spp. treatment comprised intramammary antibiotic treatment; that is, ceftiofur (Spectramast LC, Zoetis) for $5 \mathrm{~d}$ as the treatment of choice $(5 \times \$ 4.50=\$ 22.50), 20 \%$ of cows receiving systemic antibiotic antiinflammatory drugs and fluids intravenously per os $(\$ 16 \times 0.2+\$ 17.5 \times 0.2=$ $\$ 6.70$; see Streptococcus spp. above for more details on systemic antibiotics and antiinflammatory drugs and fluids calculations) and labor $(\$ 20)$, for a total cost of $\$ 49.20$. The duration of discarded milk due to antibiotics and antiinflammatory drugs was $8 \mathrm{~d}$ ( $5 \mathrm{~d}$ of Spectramast LC treatment plus $72 \mathrm{~h}$ after final intramammary ceftiofur treatment). 
Table 1. Monthly probability of pathogen-specific clinical mastitis (CM) by case number, carryover ${ }^{1}$ (if applicable), and parity

\begin{tabular}{|c|c|c|c|c|c|c|c|c|c|c|c|}
\hline CM case & Carryover & Parity & Month & $\begin{array}{l}\text { Staphylococcus } \\
\text { spp. }\end{array}$ & $\begin{array}{c}\text { Staphylococcus } \\
\text { aureus }\end{array}$ & $\begin{array}{l}\text { Streptococcus } \\
\text { spp. }\end{array}$ & $\begin{array}{l}\text { Escherichia } \\
\text { coli }\end{array}$ & $\begin{array}{l}\text { Klebsiella } \\
\text { spp. }\end{array}$ & $\begin{array}{l}\text { Other } \\
\text { treated }\end{array}$ & $\begin{array}{c}\text { Other not } \\
\text { treated }\end{array}$ & $\begin{array}{l}\text { Negative } \\
\text { culture }\end{array}$ \\
\hline \multirow[t]{12}{*}{ First case } & & 1 & 0 & 0.0007 & 0.0006 & 0.002 & 0.0009 & 0.0002 & 0.0004 & 0.0009 & 0.001 \\
\hline & & & 1 & 0.002 & 0.002 & 0.005 & 0.003 & 0.0005 & 0.006 & 0.002 & 0.006 \\
\hline & & & 2 & 0.0004 & 0.0006 & 0.002 & 0.005 & 0.0003 & 0.002 & 0.0005 & 0.007 \\
\hline & & & $3+$ & 0.0007 & 0.001 & 0.003 & 0.003 & 0.0005 & 0.0005 & 0.0006 & 0.004 \\
\hline & 0 & $2+$ & 0 & 0.0003 & 0.0003 & 0.002 & 0.0005 & 0.0002 & 0.0001 & 0.0005 & 0.002 \\
\hline & & & 1 & 0.0009 & 0.0008 & 0.005 & 0.007 & 0.003 & 0.0008 & 0.002 & 0.009 \\
\hline & & & 2 & 0.001 & 0.001 & 0.005 & 0.011 & 0.003 & 0.0006 & 0.001 & 0.013 \\
\hline & & & $3+$ & 0.001 & 0.001 & 0.006 & 0.008 & 0.002 & 0.0008 & 0.0008 & 0.009 \\
\hline & $>0$ & $2+$ & 0 & 0.0007 & 0.0006 & 0.003 & 0.002 & 0.0006 & 0.0003 & 0.002 & 0.005 \\
\hline & & & 1 & 0.003 & 0.003 & 0.013 & 0.013 & 0.006 & 0.002 & 0.003 & 0.023 \\
\hline & & & 2 & 0.002 & 0.002 & 0.009 & 0.021 & 0.005 & 0.003 & 0.002 & 0.027 \\
\hline & & & $3+$ & 0.003 & 0.003 & 0.012 & 0.013 & 0.004 & 0.002 & 0.001 & 0.020 \\
\hline \multirow{6}{*}{ Second case $^{2}$} & $\mathrm{NA}^{3}$ & 1 & 1 & 0.005 & 0.008 & 0.021 & 0.020 & 0.007 & 0.0003 & 0.003 & 0.022 \\
\hline & & & 2 & 0.002 & 0.002 & 0.004 & 0.003 & 0.000 & 0.002 & 0.003 & 0.020 \\
\hline & & & $3+$ & 0.0003 & 0.0004 & 0.001 & 0.002 & 0.0004 & 0.0007 & 0.001 & 0.009 \\
\hline & & $2+$ & 1 & 0.012 & 0.014 & 0.034 & 0.034 & 0.017 & 0.0003 & 0.002 & 0.031 \\
\hline & & & 2 & 0.001 & 0.002 & 0.010 & 0.006 & 0.003 & 0.001 & 0.003 & 0.039 \\
\hline & & & $3+$ & 0.0008 & 0.0005 & 0.004 & 0.004 & 0.0008 & 0.0005 & 0.001 & 0.020 \\
\hline \multirow{6}{*}{ Third case $^{2}$} & NA & 1 & 1 & 0.004 & 0.014 & 0.024 & 0.023 & 0.005 & 0.004 & 0.003 & 0.040 \\
\hline & & & 2 & 0.006 & 0.004 & 0.008 & 0.006 & 0.000 & 0.000 & 0.000 & 0.042 \\
\hline & & & $3+$ & 0.0006 & 0.000 & 0.0006 & 0.001 & 0.0006 & 0.0006 & 0.001 & 0.013 \\
\hline & & $2+$ & 1 & 0.011 & 0.012 & 0.042 & 0.028 & 0.022 & 0.000 & 0.002 & 0.040 \\
\hline & & & 2 & 0.003 & 0.007 & 0.018 & 0.010 & 0.003 & 0.002 & 0.002 & 0.056 \\
\hline & & & $3+$ & 0.0006 & 0.0009 & 0.005 & 0.002 & 0.001 & 0.0002 & 0.002 & 0.030 \\
\hline
\end{tabular}

${ }^{1}$ The number of cases of $\mathrm{CM}$ the cow had in the immediate preceding lactation.

${ }^{2}$ The monthly risk estimates for the second (and third) CM occurrence applied to cows that had already experienced 1 (2) case(s) of CM (of any type) within the lactation. For cases 2 and 3, months are months since the previous case of CM.

${ }^{3}$ Not applicable. 
Table 2. Average daily milk change $(\mathrm{kg})$ since onset of pathogen-specific clinical mastitis $(\mathrm{CM})$, by case, parity, and months passed (positive values are gains and negative values are losses for the month(s) since CM, as specified)

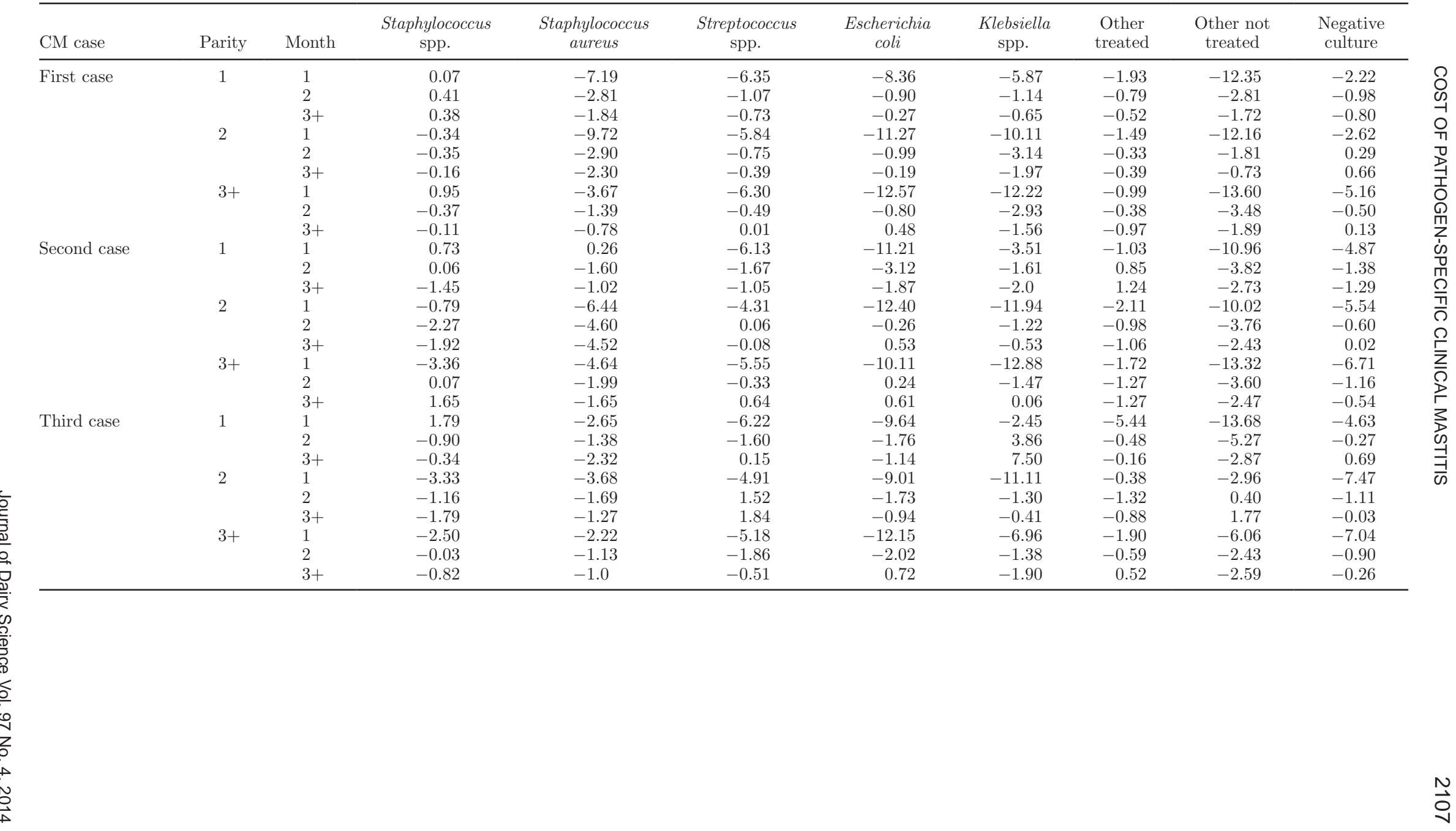




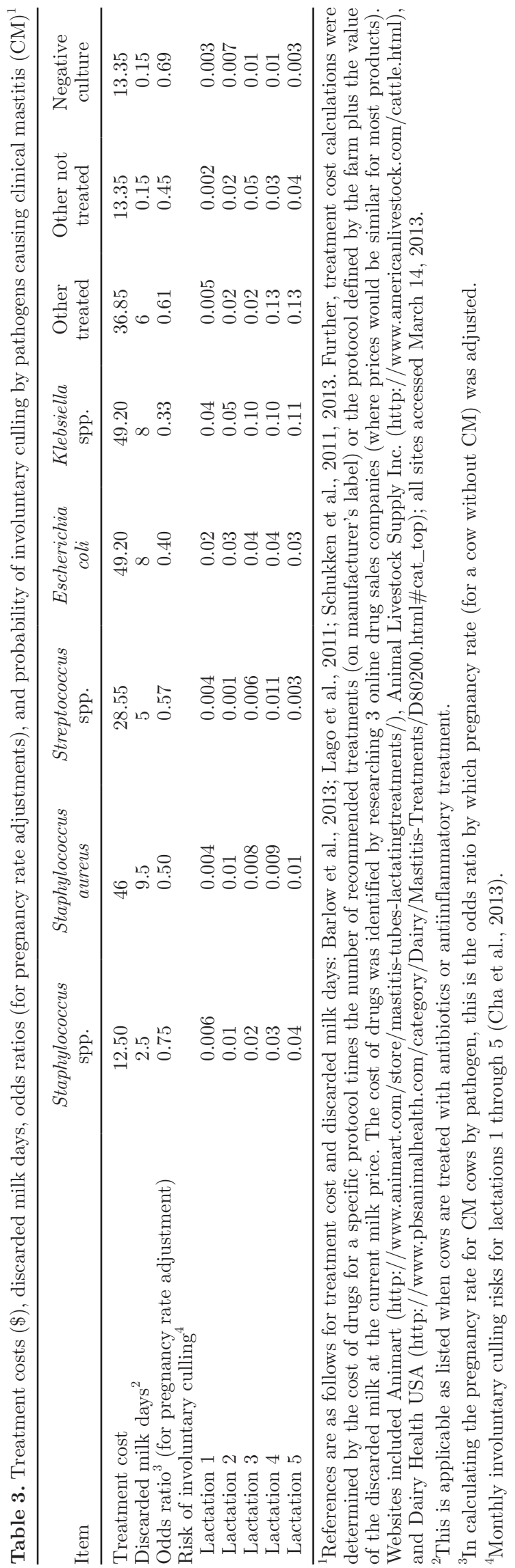

The treatment cost for the other treated category comprised antibiotics; that is, use of ceftiofur (Spectramast, Zoetis) for $3 \mathrm{~d}$ as the treatment of choice $(3 \times$ $\$ 4.50=\$ 13.50), 10 \%$ of cows receiving systemic antibiotics and antiinflammatory drugs and fluid intravenously per os $(10 \% \times \$ 33.5=\$ 3.35$; see Streptococcus spp. for more details on systemic treatment and fluids calculations) and labor ( $\$ 20)$, for a total of $\$ 36.85$. The duration of discarded milk due to antibiotics and antiinflammatory drugs was $6 \mathrm{~d}$ ( $3 \mathrm{~d}$ of Spectramast LC treatment plus 72-h withdrawal period beginning after final intramammary ceftiofur treatment).

The cost of other not-treated CM comprised $10 \%$ of cows receiving systemic antibiotics, antiinflammatory drugs, and fluids $(0.1 \times \$ 33.5=\$ 3.35$; see Streptococcus spp. for more details on systemic treatment and fluids calculations), and labor $(\$ 10)$, for a total of $\$ 13.35$. The duration of discarded milk due to antiinflammatory drugs was $0.15 \mathrm{~d}(0.1 \times 36 \mathrm{~h}=0.15 \mathrm{~d})$.

The cost of CM cases with negative culture comprised $10 \%$ of cows receiving systemic antibiotics and antiinflammatory drugs and fluids intravenously per os $(10 \% \times \$ 33.5=\$ 3.35$; see Streptococcus spp. for more details on systemic treatment and fluids calculations) and labor $(\$ 10)$, for a total of $\$ 13.35$. The duration of discarded milk due to antiinflammatory drugs was 0.15 $\mathrm{d}(0.1 \times 36 \mathrm{~h}=0.15 \mathrm{~d})$.

The probability of pregnancy was set to 0.21 if the decision was to inseminate (Bar et al., 2008a). Odds ratios that would reduce the rate of conception for each type of $\mathrm{CM}$ were applicable only for the first month after the cow got CM. If a cow contracted CM, her probability of transitioning into the pregnancy state the following month was multiplied by the formula [pregnancy rate $\times$ conception odds ratio for type of $\mathrm{CM} /(1$ - pregnancy rate + pregnancy rate $\times$ conception odds ratio for type of CM)]. The voluntary waiting period was $60 \mathrm{~d}$, the maximum allowed calving interval was $20 \mathrm{mo}$, and the involuntary culling risk at calving was 2\% (Bar et al., 2008a).

The purchase cost of a calving first-lactation animal was $\$ 1,600$, average monthly cow maintenance cost was $\$ 150$, and insemination cost/month of insemination was $\$ 20$. The average value of a calf born was $\$ 200$. The milk price was set at $\$ 0.31 / \mathrm{kg}$ and the feed cost was $\$ 0.20 / \mathrm{kg}$ of DM. The cull price for voluntarily culled cows was $\$ 0.74 / \mathrm{kg}$ of BW.

The cost of keeping a cow in the herd was separated into 2 parts: a $\$ 150$ fixed cost of keeping the cow for a month regardless of level of milk production $(7 \mathrm{~kg}$ of lactating ration DMI per day and all operating and fixed costs), and a net revenue component of $\$ 0.222$ net return $/ \mathrm{kg}$ of milk (milk price minus feed price to produce $1 \mathrm{~kg}$ of milk; Bar, 2007; Bar et al., 2008a). 
The actual milk yield of cows was divided into 2 separate parts: expected milk yield and a deviation from this expectation. Lactations were modeled as the actual yields in the first $3 \mathrm{mo}$ and a constant linear negative slope thereafter (Bar et al., 2008a). The motivation for keeping these values the same as in Bar et al. (2008a) was so that our results could be compared.

\section{Estimating CM Cost}

Following an optimization, whole-herd simulations were performed to estimate the average net returns and average cost per case of CM. The average net returns under optimization per cow per year for a herd without CM were compared with the average net returns per cow per year for a herd with CM (by pathogen), while keeping other parameters constant. Profit or loss was divided by $\mathrm{CM}$ incidence to generate the herd-average cost per case of CM. As the cost of CM was reduced under optimal treatment decisions, it is possible that the computed costs of CM differ from actual farm cost experience.

The net present value (NPV) is the current discounted value of actions where the benefits and costs of the actions are calculated until the end of the time horizon. This is achieved by discounting the various benefits and costs by an annual interest rate over that time period. The discounting factor $(\beta)$, assuming revenue and cost occur uniformly over each time period, is equal to the continuously compounding formula $\exp (-\mathrm{r})$ where $\mathrm{r}=0.08$ (interest rate); that is, $\beta=$ 0.92. The retention payoff (RPO) value is the NPV of retaining a cow compared with the NPV of her replacement: $\mathrm{NPV}_{\text {retaining }}-\mathrm{NPV}_{\text {replacing. }}$.

\section{Estimating Components of CM Cost}

The components contributing to the average cost per case; that is, reduced milk production due to CM, reduced conception risk, treatment cost, and milk discarded due to treatment and risk of mortality, were estimated by sequentially adding the effects of these components and comparing the difference in the average cost/case.

\section{Exit from the Herd}

Exit from the herd could be due to 2 reasons: (1) voluntary culling based on the model's recommendation, or (2) involuntary culling. Involuntary culling could be due to death, euthanasia, or cows sold for slaughter for reasons other than milk yield, pregnancy, or CM (i.e., not determined directly from the model).

\section{Sensitivity Analyses}

Given that parameters such as milk price, pregnancy rate, and replacement cost can vary over time and by farm, a sensitivity analysis was performed to evaluate how an increase or decrease of $20 \%$ in each of these values individually affected the percentage of $\mathrm{CM}$ cases in the herd and the average cost per case.

\section{RESULTS}

\section{Cost of Pathogen-Specific CM}

The net returns (US\$) per cow and year for the basic scenario (with all CM included) was $\$ 507$, where the incidence rate of CM (cases per 100-cow years) was 35.6 , of which $91.8 \%$ of cases were recommended for treatment under an optimal replacement policy (Table 4).

The cost per case of CM was $\$ 216.12$ (average cost per cow in the herd/incidence; $\$ 76.94 / 0.356)$. The CM cases (total of 35.6 cases per 100 cow-years) comprised Staphylococcus spp. (1.6\%), Staph. aureus (1.8\%), Streptococcus spp. (6.9\%), E. coli (8.1\%), Klebsiella spp. $(2.2 \%)$, other treated cases $(1.1 \%)$, other not treated cases $(1.2 \%)$, and negative culture cases $(12.7 \%)$. The average cost per case even under optimal decisions was greatest for Klebsiella spp. (\$477), followed by E. coli (\$361), other treated cases (e.g., Pseudomonas; \$297), and other not-treated cases (e.g., T. pyogenes; \$280). This was followed by the gram-positive pathogens, where the greatest cost per case was due to Staph. aureus (\$266), Streptococcus spp. (\$174), Staphylococcus spp. (\$135), and negative culture cases (\$115).

The model recommended treatment, rather than replacement, for most $\mathrm{CM}$ cases by pathogen (all $>85 \%$ ). This recommendation to treat was greatest for Staphylococcus spp. (98.5\%) and lowest for Klebsiella spp. cases $(86.2 \%)$.

The components contributing to the average cost per case; that is, reduced milk production due to CM, reduced conception, treatment cost, milk discarded due to treatment, and risk of mortality, are presented in Table 5.

\section{Effects of Changes in Exogenous Factors on the Cost of Pathogen-Specific CM}

In general, a $20 \%$ increase in milk price resulted in an increase in the average cost per case of CM. This same trend was observed as replacement cost increased by $20 \%$ (Table 6). The incidence of CM increased overall when replacement cost and pregnancy rate increased by $20 \%$. 
Table 4. The effects of different pathogens causing clinical mastitis $(\mathrm{CM})$ on the percentage of CM cases treated and the average cost of CM and average cost per case, following an optimal replacement policy (all costs in US\$, rounded to the nearest dollar)

\begin{tabular}{lrrrr}
\hline Item & $\begin{array}{c}\text { CM } \\
\text { cases }^{1}\end{array}$ & $\begin{array}{c}\text { CM cases } \\
\text { treated (\%) }\end{array}$ & $\begin{array}{c}\text { Average costs of CM } \\
\text { per cow in the herd }\end{array}$ & $\begin{array}{c}\text { Average cost } \\
\text { per case }\end{array}$ \\
\hline Basic scenario (including all CM) & 35.6 & 91.8 & 77 & 216 \\
Staphylococcus spp. & 1.6 & 98.5 & 2 & 135 \\
Staphylococcus aureus & 1.8 & 89.2 & 5 & 266 \\
Streptococcus spp. & 6.9 & 92.3 & 29 & 174 \\
Escherichia coli & 8.1 & 87.1 & 10 & 361 \\
Klebsiella spp. & 2.2 & 86.2 & 3 & 477 \\
Other treated cases & 1.1 & 95.9 & 3 & 297 \\
Other not treated cases & 1.2 & 91.4 & 15 & 280 \\
Negative culture cases & 12.7 & 94.5 & & 115 \\
\hline
\end{tabular}

${ }^{1}$ Incidence of CM (cases per 100 cow-years).

${ }^{2}$ Percentage of treated CM cows per all CM cows.

${ }^{3}$ Average cost per CM case.

\section{RPO Value of Open Healthy and Mastitic Cows}

Our economic model calculated the RPO for cows depending on the cow's individual characteristics. Figure 2 shows an example of a hypothetical cow's RPO under an optimal policy for cows free of CM and with CM by pathogen in a given month, specific to an open (nonpregnant), second-lactation cow with $\geq 1$ case of CM in the previous lactation and average permanent and temporary milk yields per 305-d lactation. The optimal policy recommended by the model: (1) keep (and treat if CM) and not inseminate, (2) keep (and treat if CM) and inseminate, or (3) replace is also illustrated by the symbols in the figures.

The RPO of cows at calving was $\$ 1,133, \$ 1,018$, $\$ 951, \$ 770, \$ 738, \$ 1,078, \$ 872, \$ 869$, and $\$ 580$ for no CM, Staphylococcus spp., Streptococcus spp., Staph. aureus, E. coli, negative culture, other not treated, other treated, and Klebsiella spp., respectively, as illustrated in Figure 2. The average cost of mastitis occurring at the time of calving was calculated by subtracting the $\mathrm{RPO}$ for the pathogen-specific CM from the RPO for no CM. The average cost of mastitis at the time of calving was thus $\$ 115(\$ 1,133-\$ 1,018), \$ 182(\$ 1,133-$ $\$ 951), \$ 363(\$ 1,133-\$ 770), \$ 395(\$ 1,133-\$ 738), \$ 55$ $(\$ 1,133-\$ 1,078), \$ 261(\$ 1,133-\$ 872), \$ 264(\$ 1,133$ - \$869), and $\$ 553(\$ 1,133$ - \$580) for Staphylococcus spp., Streptococcus spp., Staph. aureus, E. coli, negative culture, other not treated, other treated, and Klebsiella spp., respectively. When the RPO is negative, it is more profitable to cull the cow than to keep her (and treat her if she has CM). This was observed in mo 12 for a CM-free case; mo 11 for Staphylococcus spp.; mo 11 for negative culture; mo 9 for other treated, other not treated, and Strep. spp.; and mo 7 for E. coli, Klebsiella spp., and Staph. aureus. Figure 2 illustrates the recommended policy until mo 15; the model recommended that open cows in mo $15(\sim 460 \mathrm{DIM})$ and onward be replaced.

\section{Endogenous Factors Affecting the Cost of CM}

The optimal decision and cost of CM depends on endogenous factors, such as the permanent (genetic) milk yield potential of the cow, pregnancy status, and lactation, as shown in Table 7.

Table 5. Breakdown of average cost of a clinical mastitis (CM) case into components (milk loss, reduction in conception, treatment cost, milk discarded due to treatment, and risk of mortality) contributing to the average cost per case for pathogen-specific CM

\begin{tabular}{|c|c|c|c|c|c|c|}
\hline \multirow[b]{2}{*}{ Pathogen } & \multicolumn{5}{|c|}{ Components contributing to average cost per case of CM ( $\%$ of average cost/case) } & \multirow[b]{2}{*}{$\begin{array}{c}\text { Average } \\
\text { cost/case }(\$)\end{array}$} \\
\hline & $\begin{array}{l}\text { Milk } \\
\text { loss }\end{array}$ & $\begin{array}{c}\text { Reduced } \\
\text { conception }\end{array}$ & $\begin{array}{l}\text { Treatment } \\
\text { cost }\end{array}$ & $\begin{array}{l}\text { Discarded } \\
\text { milk }\end{array}$ & $\begin{array}{c}\text { Risk of } \\
\text { mortality }\end{array}$ & \\
\hline Staphylococcus spp. & $2(1)$ & $30(22)$ & $22(16)$ & $16(12)$ & $64(48)$ & 134 \\
\hline Staphylococcus aureus & $62(23)$ & $33(12)$ & $75(28)$ & $61(23)$ & $34(13)$ & 265 \\
\hline Streptococcus spp. & $29(17)$ & $44(25)$ & $48(28)$ & $33(19)$ & $20(11)$ & 174 \\
\hline Escherichia coli & $44(12)$ & $56(16)$ & $78(22)$ & $50(14)$ & $132(37)$ & 360 \\
\hline Klebsiella spp. & $64(13)$ & $26(5)$ & $75(16)$ & $48(10)$ & $263(55)$ & 476 \\
\hline Other treated & $21(7)$ & $75(25)$ & $61(21)$ & $37(13)$ & $102(34)$ & 296 \\
\hline Other not treated & $106(37.9)$ & $53(18.9)$ & $22(7.9)$ & $1(0.4)$ & $98(35)$ & 280 \\
\hline Negative culture & $26(22)$ & $34(30)$ & $22(20)$ & $1(1)$ & $32(28)$ & 115 \\
\hline
\end{tabular}




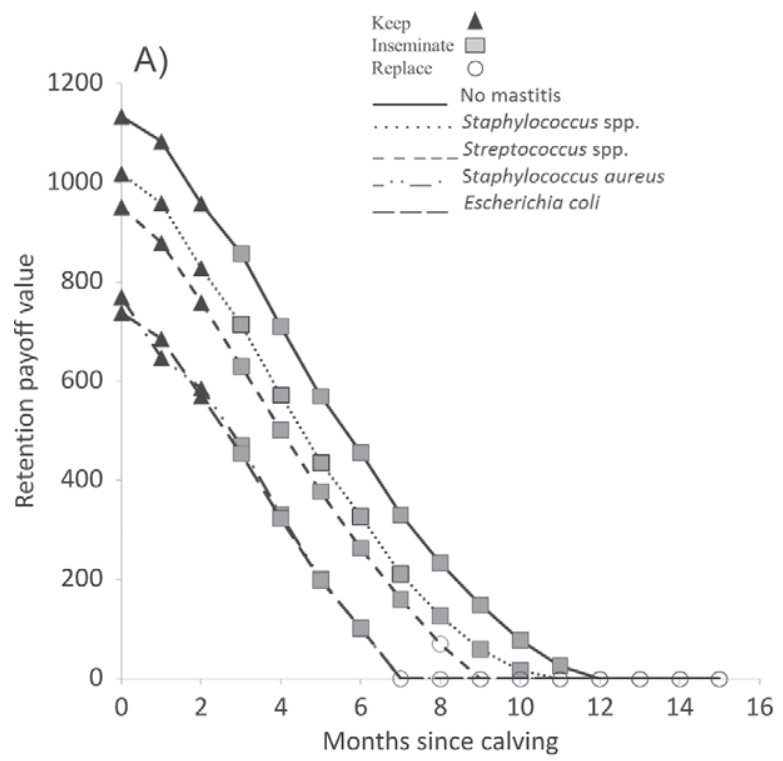

B)

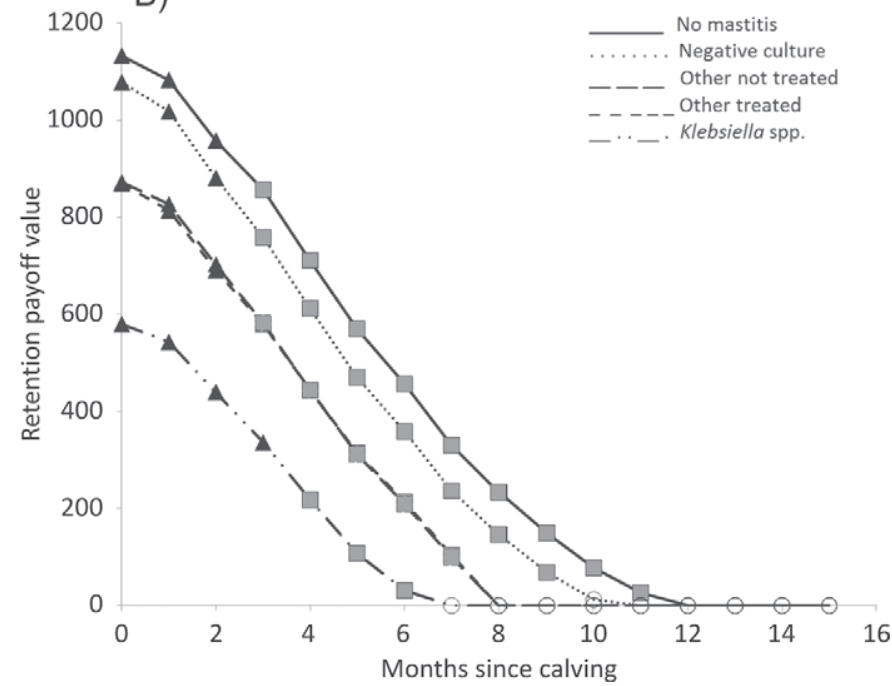

Figure 2. Retention payoff values for a hypothetical open (nonpregnant) cow in lactation 2 with $\geq 1$ case of clinical mastitis in the previous lactation, with average permanent and temporary milk yields, with either no mastitis or a case of mastitis with the indicated pathogen (first case only) in the month since calving: (A) Staphylococcus spp., Streptococcus spp., Escherichia coli, and Staphylococcus aureus; (B) negative culture, other treated, other not treated, and Klebsiella spp.

These average costs are for a cow 4 mo after calving with no $\mathrm{CM}$ in the previous lactation. The average cost was greater in pregnant cows compared with open cows. Younger cows also had a greater average cost compared with older cows. The average cost increased as permanent milk yield potential increased. Although the pathogen with the greatest average cost varied by pregnancy status and genetic milk yield potential, Klebsiella spp. and E. coli had the largest average costs

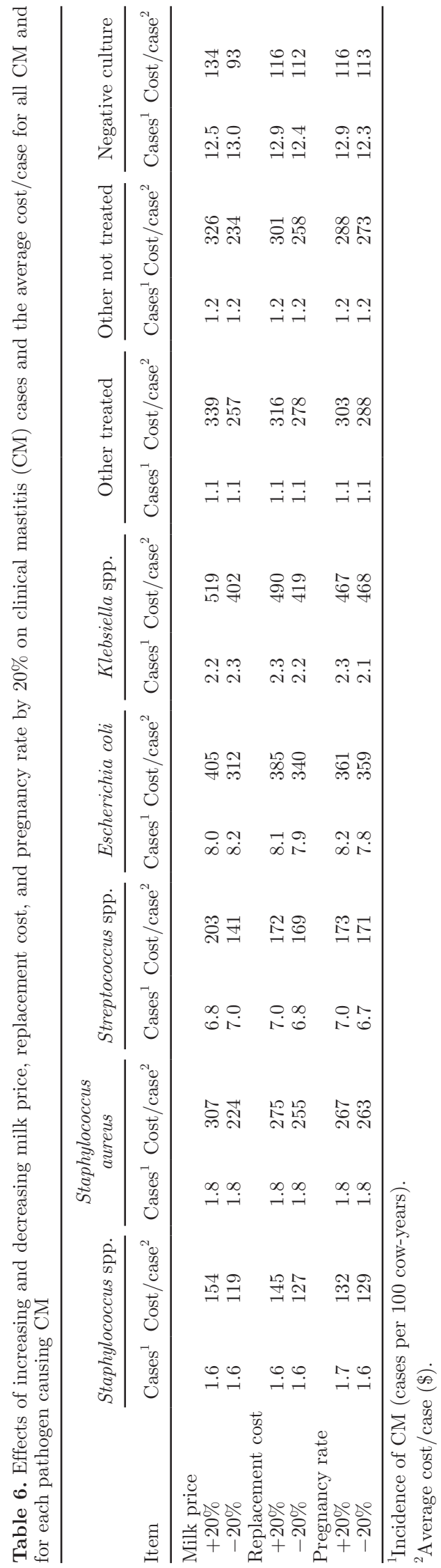

Journal of Dairy Science Vol. 97 No. 4, 2014 
Table 7. Average cost (in US\$) of a first case of pathogen-specific clinical mastitis (CM) in cows with no CM in the previous lactation and different levels (low, average, high) of permanent (genetically determined) milk yield potential 4 mo after calving and open (i.e., not pregnant) or pregnant, obtained by the insemination and replacement optimization model

\begin{tabular}{|c|c|c|c|c|c|c|c|c|c|c|c|c|c|c|c|c|}
\hline \multirow[b]{3}{*}{ Lactation } & \multicolumn{16}{|c|}{ Low milk yield potential } \\
\hline & \multicolumn{8}{|c|}{ Open } & \multicolumn{8}{|c|}{ Pregnant } \\
\hline & Sta & S. aur & Str & E. coli & Kleb & Otht & Othn & Negc & Sta & S. aur & Str & E. coli & Kleb & Otht & Othn & Negc \\
\hline 1 & 41 & 119 & 119 & 119 & 119 & 114 & 119 & 107 & 116 & 256 & 222 & 256 & 256 & 215 & 256 & 186 \\
\hline 2 & 72 & 241 & 173 & 231 & 241 & 152 & 143 & 53 & 136 & 333 & 229 & 314 & 361 & 226 & 218 & 113 \\
\hline \multirow[t]{4}{*}{4} & 55 & 221 & 127 & 214 & 222 & 146 & 156 & 103 & 125 & 290 & 189 & 285 & 307 & 231 & 231 & 164 \\
\hline & \multicolumn{16}{|c|}{ Average milk yield potential } \\
\hline & \multicolumn{8}{|c|}{ Open } & \multicolumn{8}{|c|}{ Pregnant } \\
\hline & Sta & S. aur & Str & E. coli & Kleb & Otht & Othn & Negc & Sta & S. aur & Str & E. coli & Kleb & Otht & Othn & Negc \\
\hline 1 & 165 & 411 & 292 & 436 & 532 & 287 & 354 & 241 & 184 & 381 & 286 & 418 & 501 & 285 & 326 & 240 \\
\hline 2 & 190 & 433 & 258 & 445 & 556 & 321 & 320 & 148 & 201 & 405 & 268 & 440 & 542 & 324 & 310 & 167 \\
\hline \multirow[t]{4}{*}{4} & 163 & 324 & 208 & 345 & 457 & 379 & 292 & 171 & 184 & 322 & 217 & 366 & 509 & 454 & 291 & 185 \\
\hline & \multicolumn{16}{|c|}{ High milk yield potential } \\
\hline & \multicolumn{8}{|c|}{ Open } & \multicolumn{8}{|c|}{ Pregnant } \\
\hline & Sta & S. aur & Str & E. coli & Kleb & Otht & Othn & Negc & Sta & S. aur & Str & E. coli & Kleb & Otht & Othn & Negc \\
\hline 1 & 209 & 456 & 329 & 588 & 806 & 331 & 375 & 264 & 222 & 415 & 315 & 536 & 715 & 321 & 339 & 259 \\
\hline 2 & 243 & 499 & 266 & 603 & 801 & 429 & 425 & 183 & 247 & 457 & 278 & 569 & 741 & 413 & 394 & 198 \\
\hline 4 & 243 & 355 & 238 & 456 & 698 & 659 & 381 & 193 & 246 & 348 & 243 & 451 & 689 & 669 & 351 & 205 \\
\hline
\end{tabular}

${ }^{1}$ Sta $=$ Staphylococcus spp.; S. aur = Staphylococcus aureus $;$ Str $=$ Streptococcus spp.; E. coli $=$ Escherichia coli $;$ Kleb $=$ Klebsiella spp.; Otht $=$ other treated; Othn $=$ other not treated; Negc = negative culture. 
overall. This reflects the average cost per case trend seen in Table 5.

\section{Exit from the Herd (Voluntary and Involuntary Culling)}

The percentage of involuntary culling over a year was $10.3 \%$, and the percentage of voluntary culling was $20.2 \%$, for a total culling of $30.5 \%$ when all $\mathrm{CM}$ was included in the model. The total exit increased to $32.9 \%$ ( $10.2 \%$ involuntary and $22.7 \%$ voluntary culling) when milk price increased by $20 \%$, and decreased to $28.6 \%$ (10.5 and $18.1 \%$ ) when milk price was decreased by $20 \%$. The total exit was decreased to $29.1 \%$ (10.5 and 18.6\%) when replacement cost was increased by $20 \%$, and increased to $33.2 \%$ (10.1 and $23.1 \%$ ) when replacement cost was decreased by $20 \%$. When pregnancy rate was increased by $20 \%$, the total exit was decreased to $28.8 \%$ (10.6 and $18.2 \%$ ) and when pregnancy rate was reduced by $20 \%$, total exit increased to $33.5 \%$ (9.9 and $23.6 \%$ )

\section{DISCUSSION}

The objective of this study was to develop and solve an economic optimization model that provides dairy farmers optimal decisions for management of their cows with CM. The average cost per case even under optimal decisions was greatest for Klebsiella spp. (\$477), followed by E. coli (\$361), other treated cases (e.g., Pseudomonas; $\$ 297$ ), other not treated cases (e.g., T. pyogenes; \$280), Staph. aureus (\$266), Streptococcus spp. (\$174), Staphylococcus spp. (\$135), and negative culture (\$115). The optimal recommended time for replacement was up to 5 mo earlier for cows with $\mathrm{CM}$ compared with cows without CM. This earlier recommended replacement time represents the incorporation of the economic losses for each pathogen causing CM. The exact contribution of each of the component losses to the cost per case of CM differed depending on the pathogen involved. Although the results from this study are specific to the study herds, the parameter estimates implemented in this model may be altered to generate results specific to any other farm. Furthermore, this economic model is a valuable tool for identifying cow rankings according to their projected value based on current disease, pregnancy, and milk yield status. This ranking could facilitate dairy farmers' decisions regarding which cows should be kept and which cows are more economical to replace given a fixed number of replacements available (Kristensen and Thysen, 1991).

By including pathogen-specific CM information, the most detailed information available at this time, the model more closely represented the host-pathogen dynamics that are actually occurring on farm. Previously, the CM-causing agents were pooled into groups; that is, generic (Bar et al., 2008a) or gram classificationspecific (Cha et al., 2011), meaning that all parameter estimates were averages across group(s).

By stratifying by pathogen, we were able to determine that mortality and treatment cost contribute more significantly to the cost of pathogen-specific CM, and that the effect of reduced milk production due to $\mathrm{CM}$ was actually less than when all CM cases were combined into one group (Bar et al., 2008a) or stratified by groups based on gram-positive (Streptococcus spp., Staphylococcus spp., Staph. aureus) versus gram-negative (E. coli, Klebsiella spp.) versus other (other treated, other not treated CM, negative culture) (Cha et al., 2011). This is partly attributable to the data parameters being different across periods, as more data were collected with each progressive study. Better decisions, however, result in lower costs, so this pathogen-specific model results in an overall lower computed cost per case of CM. In this study, we identified that other CM (i.e., those that are not gram-positive or gram-negative CM) actually have a high cost per case, comparable with gram-positive CM cases. The total percentage of cows recommended for culling in our study was lower than that in Cha et al. (2011) at $30.6 \%$, mainly due to a lower involuntary culling percentage. The percentage of cows recommended for culling by the economic model (the voluntary culls), however, was similar. Note that replacements were assumed to be readily available at a constant and reasonable cost.

As expected, the average cost of CM generally increased when cows were at their greatest milk yield potentials. The average cost of CM was less for lower lactation cows. Although we observed similar trends in average costs across different permanent milk yield levels and across lactations as reported by Cha et al. (2011), we found average costs were lower for open cows compared with pregnant cows. In the Cha et al. (2011) study, the effects of reduced conception were assumed to be present for a period of $3 \mathrm{mo}$ after a CM case. Based on more recent data, we now only allowed for reduced conception for a period of 1 mo after a case of CM (Hertl et al., 2010).

It is difficult to validate animal replacement economic models because existing models often differ in their structure and parameter values. Interestingly, the net return per year from our study (\$494) was comparable to the expected NPV of $£ 285.50$ (approximately $\$ 457$ ) in a study by Yalcin and Stott (2000); the latter model had a time horizon of $20 \mathrm{yr}, 12$ lactations, 15 milk yield states, and 11 SCC states. The net return in our current study was greater than that from the generic CM study by Bar et al. (2008; \$355), and the grampositive, gram-negative, and other CM study by Cha et 
al. (2011; \$357.35). Differences in these values are attributed to the varying model structure and parameter estimates adopted. In the model by Bar et al. (2008a), CM was included as one group not differentiated by culture classes. This meant that the effects of CM (i.e., repeated risks, milk loss, mortality risks, and reduced conception) were all for generic CM and not culture classes as in the case of our model.

Only a few studies have examined the cost of pathogen-specific CM, including Østergaard et al. (2005) and Sørensen et al. (2010). In the study by Sørensen et al. (2010), economic values for pathogen-specific CM were estimated using a stochastic simulation model (SimHerd IV). The simulations were conducted over time with weekly time increments, other diseases as well as severity of CM were included, and an annual interest rate of $4 \%$ was used (compared with $8 \%$ in our study). Although we found that the average cost/case was generally greater for E. coli and Klebsiella spp., the Sørensen et al. (2010) study found the opposite trend, where the cost per case was greater for Staph. aureus [€570 (\$725)] and CNS [€380 (\$483)], and less for E. coli [€206 (\$262)] and Strep. dysgalactiae and Strep. uberis [€149 (\$189)]. The model by Sørensen et al. (2010) did not model contagious spread between herdmates, under the same assumption as our dynamic program. The difference in costs per case may be due to the mortality risks we adopted (Cha et al., 2013) and, based on this, it is not surprising that risk of mortality contributed largely to the cost per case in our study, especially for CM caused by E. coli and Klebsiella spp.

The average cost per case for each pathogen is an economic consequence of the assimilation of the pathogen-specific CM effects (i.e., milk loss, reduced conception, treatment cost, discarded milk days, and mortality risk) with which we parameterized our model. By including discarded milk due to treatment after adjusting for the loss of milk due to CM, our results were more accurate than if the discarded milk was accounted for without considering the initial decrease in milk due to CM. Through scenarios analyses, we were able to break down the contribution of each effect to the average cost per case by pathogen (Table 5). It may seem counterintuitive that some pathogens may be treated with antibiotics given that the milk loss due to days of discarded milk following antibiotic therapy is greater than the effect of reduced milk production, but we forced cows to be treated for ethical reasons. It is noteworthy that milk loss for $E$. coli cases in this study was representative of farms that use a $\mathrm{J} 5$ vaccine, which has been demonstrated to reduce milk loss due to E. coli (Wilson et al., 2007).

The sensitivity analyses of milk price, replacement cost, and pregnancy rate were performed to identify the effect of these factors on the direction and magnitude of the average cost per case and incidence of CM. When milk price was increased by $20 \%$, the average cost per case increased because the production-limiting effects of CM had a greater effect at higher milk prices. The cost of CM was reduced when replacement cost was decreased by $20 \%$, as an increase in the number of replacements would lead to an overall younger herd of animals with an overall lower incidence of CM compared with an older herd of animals. The increased incidence of $\mathrm{CM}$ when pregnancy rate was increased by $20 \%$ is explained by there being more cows being kept in the herd, as pregnancy adds value to the cow, thereby leading to more older cows in the herd, and a greater incidence of $\mathrm{CM}$ compared with a younger group of animals. These trends are in agreement with those from our previous studies (Bar et al., 2008a; Cha et al., 2011).

Although the cost of CM was greatest for pregnant cows in general, as would be expected, this was not the case in some instances (Table 7). This is explained by open cows having the added effect of reduced fertility (as opposed to pregnant cows already with calf). Other factors are also involved (e.g., permanent and temporary milk yield, pathogen-specific $\mathrm{CM}$ ), so this trend was not consistent.

From mo 3 in lactation, the first month a cow can be inseminated, we observed that until the optimal policy becomes replacement (the latest being at mo 12), the model recommends that the cow be inseminated regardless of CM status (in the case of Klebsiella spp., this was from mo 4 onward; Figure 2). Because the length of each lactation was set at a maximum of 20 mo and any cow that became pregnant from mo 13 on would be automatically replaced at the end of the lactation, any open cow from mo 12 onward was recommended for replacement. The point at which a cow was recommended for replacement could be different if the maximum number of months were changed; however, it is necessary to model a maximum end point for the lactation. We also used a constant pregnancy rate of $21 \%$ throughout lactation for primiparous and multiparous cows; if we had modeled pregnancy rate as decreasing through lactation, the optimal decision might not have been to inseminate each month until a cow is replaced. This would depend on the value of the decision to keep the cow (and treat her if she has CM) compared with the decision to inseminate her, which is a function of the probability of pregnancy, the expected gain from pregnancy, and the cost of insemination.

Although cow ranking tools are currently available (Cabrera, 2012; Eicker, 2013), none of the existing tools incorporate detailed information relating to diseases or $\mathrm{CM}$ but rather focus on reproductive and milk pro- 
duction issues only. In our study, the incidence of CM was 35.5 per 100 cow-years. We have previously shown that $\mathrm{CM}$ is a production-limiting disease based upon its effects on milk yield, conception, and mortality risk. By including this detailed information on the effects of $\mathrm{CM}$, the economically optimal trajectory of a cow's life has been determined, based on the probability of her contracting diseases in the future and subsequent losses, which in turn affects the decision taken at the current time. Inclusion of this detailed CM information, costs per case per pathogen, as well as cow value (ascertained from the economic model and which is used to calculate $\mathrm{RPO}$ ), better represents the reality of losses due to CM on farm under an optimal replacement policy. These additional losses, which to date have not been directly incorporated into any commercially available software, are attributed to over one-third of cases per 100 cowyears.

Many farms do not have a replacement policy based upon formal maximization of net returns. The drawback of not having a formal optimal replacement policy in place is that those farms are not able to accurately weigh the long-term benefits of replacing a cow compared with keeping her. The advantage of an economic model is that this calculation is performed for the farmer; our model incorporates hundreds of parameter estimates, which are essential to determining whether replacement is optimal or not in a given situation, with the aim of maximizing discounted net returns. The risk exists that without an optimal replacement policy in place, farmers keep cows longer in the herd than is optimal, when it would actually be economically optimal to replace them with a heifer given the circumstances both the cow and her replacement are expected to encounter (i.e., risk of $\mathrm{CM}$, effect on milk yield, conception rate, and mortality risk).

Given that the quantity of milk produced is by far the most important determinant of net return in a dairy operation, the ideal economic optimization model would contain very detailed information on the lactation curve of dairy cows while accounting for seasonality. In the current model, the severity of individual CM cases was not included because adding this additional information would increase the state space, rendering it difficult for the model to reach optimal solutions. Furthermore, although the replacement heifers in this study follow a skewed distribution toward genetic improvement (a reflection of what is occurring on farms), we did not account for each successive replacement to be an improvement over the previous replacement. These considerations were beyond the scope of this study. However, given the flexibility of our model, the model can readily be expanded by including more diseases of importance as well as other significant production effects such as genetic improvements and more detailed lactation effects. Those efforts will require the collection of additional data and additions to the model.

Key assumptions of the model include the following: (1) a constant herd size is maintained, (2) a replacement heifer is readily available, and (3) a stable market is present for male beef calves. These assumptions are the same as those applicable to the generic CM model (Bar et al., 2008a). Unlike the generic CM model, we included only 5 lactations (as opposed to 8 lactations), as 5 lactations includes over $98 \%$ of cows in the herds that we studied (Cha et al., 2013). By reducing the number of lactations, we could curb the prohibitive effects of a large state space, otherwise known as the curse of dimensionality, even with adding CM pathogen details. Even though inclusion of a carryover state significantly increased the state space of the model, it became necessary to include this information because we found that the risk of $\mathrm{CM}$ differs depending on whether a cow suffered from cases of $\mathrm{CM}$ in the previous lactation.

In our study, the stage length was 1 mo, hence, milk production parameters were assumed constant across 1 mo, although we did have access to daily milk yields. The first month, however, was divided into the first $3 \mathrm{~d}$ after calving and the remainder of the month, so that the immediate effects of calving could be accounted for in the first $3 \mathrm{~d}$. A daily time step would have expanded the state space enormously and it is not clear whether the increased benefits would have been sufficient compared with the benefits of modeling more detail elsewhere. Nielsen et al. (2010) developed a model with a daily time step with Bayesian updating to predict the performance of cows in the herd; however, their focus was milk yield and not dairy cattle diseases.

In addition to calculating the cost of disease and optimal replacement decisions, our model can be used to investigate the value of different control strategies, such as vaccination, as was explored in the generic CM model (Bar et al., 2008b), as well as decisions around treatment and the type of treatment for CM (Halasa, 2012). One possibility would be to assess different control strategies specific to each pathogen-specific CM.

Inclusion of additional information pertaining to other diseases of importance in dairy cattle, details of the milk yield distribution, and genetic improvements would also add value to the existing model and could form the basis for future research efforts. Moreover, the value of information (i.e., monetary losses or gains from having information on $\mathrm{CM}$ at the pathogen-specific or gram-specific level), compared with merely knowing that the cow is suffering from CM, would be useful. 


\section{CONCLUSIONS}

The dynamic programming model developed and solved here generates optimal economic decisions for diseased cows experiencing pathogen-specific CM. The recommendations are specific to an individual cow, and thus depend on the permanent milk yield potential, lactation number, month of lactation, pathogen or pathogen group causing CM, temporary milk yield and pregnancy status, costs, and prices. In general, the average cost per case was greatest for Klebsiella spp. and E. coli CM. Optimal recommended time for replacement was up to 5 mo sooner for cows with CM compared with cows without CM. Furthermore, although the parameter estimates implemented in this model are specific to the dairy farms in this study, the results should prove useful to farmers with cows in similar management conditions. In addition, cow characteristics and model parameters may be altered to produce results unique to any farm. Cow rankings facilitate decisions regarding which cow to keep (and treat if she has CM) and which cow to cull based on current cow characteristics. In our model, this includes not only milk production and reproduction traits, but also detailed CM information. The structure that was modeled permits easier inclusion of addition CM states or other diseases in future research. This model can be used to assist decisions of dairy farmers with regard to their diseased cows.

\section{ACKNOWLEDGMENTS}

This project was supported by the Agriculture and Food Research Initiative Competitive Grant no. 201065119-20478 from the USDA National Institute of Food and Agriculture (Washington, DC). The authors thank the owners and personnel from the 5 dairies, the personnel of the Ithaca, Canton, and Geneseo Regional Laboratories of Quality Milk Production Services for their valuable cooperation, and Doron Bar (SCR Engineers Ltd., Netanya, Israel), for valuable discussions.

\section{REFERENCES}

Bar, D. 2007. Cost of generic clinical mastitis in dairy cows. PhD Thesis. Cornell University, Ithaca, NY.

Bar, D., L. W. Tauer, G. Bennett, R. N. González, J. A. Hertl, Y. H. Schukken, H. F. Schulte, F. L. Welcome, and Y. T. Gröhn. 2008a. The cost of generic clinical mastitis in dairy cows as estimated using dynamic programming. J. Dairy Sci. 91:2205-2214.

Bar, D., L. W. Tauer, G. Bennett, R. N. González, J. A. Hertl, H. F. Schulte, Y. H. Schukken, F. L. Welcome, and Y. T. Gröhn. 2008b. Use of a dynamic programming model to estimate the value of clinical mastitis treatment and prevention options utilized by dairy producers. Agric. Syst. 99:6-12.

Barbano, D. M., Y. Ma, and M. V. Santos. 2006. Influence of raw milk quality on fluid milk shelf life. J. Dairy Sci. 89(E-Suppl.):E15E19.
Barlow, J. W., R. N. Zadoks, and Y. H. Schukken. 2013. Effect of lactation therapy on Staphylococcus aureus transmission dynamics in two commercial dairy herds. BMC Vet. Res. 9:28.

Cabrera, V. E. 2012. A simple formulation and solution to the replacement problem: A practical tool to assess the economic cow value, the value of a new pregnancy, and the cost of a pregnancy loss. J. Dairy Sci. 95:4683-4698.

Cha, E., D. Bar, J. A. Hertl, L. W. Tauer, G. Bennett, R. N. González, Y. H. Schukken, F. L. Welcome, and Y. T. Gröhn. 2011. The cost and management of different types of clinical mastitis in dairy cows estimated by dynamic programming. J. Dairy Sci. 94:4476-4487.

Cha, E., J. A. Hertl, D. Bar, and Y. T. Gröhn. 2010. The cost of different types of lameness in dairy cows calculated by dynamic programming. Prev. Vet. Med. 97:1-8.

Cha, E., J. A. Hertl, Y. H. Schukken, F. L. Welcome, and Y. T. Gröhn. 2013. The effect of repeated episodes of bacteria specific clinical mastitis on mortality and culling in Holstein dairy cows. J. Dairy Sci. 96:4993-5007.

De Vries, A. 2006. Economic value of pregnancy in dairy cattle. J. Dairy Sci. 89:3876-3885.

Demeter, R. M., A. R. Kristensen, J. Dijkstra, A. G. Oude Lansink, M. P. Meuwissen, and J. A. van Arendonk. 2011. A multi-level hierarchic Markov process with Bayesian updating for herd optimization and simulation in dairy cattle. J. Dairy Sci. 94:5938-5962.

Eicker, S. 2013. Cow value - Dairy cow decision aid. Accessed May 15, 2013. http://www.dairyone.com/Publications/TechDocs/CowValueDC305.htm.

Gröhn, Y. T., D. J. Wilson, R. N. González, J. A. Hertl, H. Schulte, G. Bennett, and Y. H. Schukken. 2004. Effect of pathogen-specific clinical mastitis on milk yield in dairy cows. J. Dairy Sci. 87:3358-3374.

Halasa, T. 2012. Bioeconomic modeling of intervention against clinical mastitis caused by contagious pathogens. J. Dairy Sci. 95:57405749 .

Hertl, J. A., Y. T. Gröhn, J. D. G. Leach, D. Bar, G. J. Bennett, R. N. González, B. J. Rauch, F. L. Welcome, L. W. Tauer, and Y. H. Schukken. 2010. Effects of clinical mastitis caused by grampositive and gram-negative bacteria and other organisms on the probability of conception in New York State Holstein dairy cows. J. Dairy Sci. 93:1551-1560.

Hertl, J. A., Y. H. Schukken, D. Bar, G. J. Bennett, R. N. González, B. J. Rauch, F. L. Welcome, L. W. Tauer, and Y. T. Gröhn. 2011. The effect of recurrent episodes of clinical mastitis caused by gram-positive and gram-negative bacteria and other organisms on mortality and culling in Holstein dairy cows. J. Dairy Sci. 94:4863-4877.

Houben, E. H. P., R. B. M. Huirne, A. A. Dijkhuizen, and A. R. Kristensen. 1994. Optimal replacement of mastitic cows determined by a hierarchic Markov process. J. Dairy Sci. 77:2975-2993.

Kristensen, A. R. 1988. Hierarchic Markov processes and their applications in replacement models. Eur. J. Oper. Res. 35:207-215.

Kristensen, A. R. 1991. Maximization of net revenue per unit of physical output in Markov decision processes. Eur. Rev. Agric. Econ. $18: 231-244$.

Kristensen, A. R. 2003. A general software system for Markov decision processes in herd management applications. Comput. Electron. Agric. 38:199-215.

Kristensen, A. R., and E. Jørgensen. 2000. Multi-level hierarchic Markov processes as a framework for herd management support. Ann. Oper. Res. 94:69-89.

Kristensen, A. R., E. Jørgensen, and N. Toft. 2010. Herd Management Science II: Advanced Topics. University of Copenhagen, Faculty of Life Sciences. Academic Books, Copenhagen, Denmark.

Kristensen, A. R., and R. Thysen. 1991. Ranking of dairy cows for replacement. Acta Agric. Scand. 41:295-303.

Lago, A., S. M. Godden, R. Bey, P. L. Ruegg, and K. Leslie. 2011. The selective treatment of clinical mastitis based on on-farm culture results: I. Effects on antibiotic use, milk withholding time, and short-term clinical and bacteriological outcomes. J. Dairy Sci. 94:4441-4456. 
Nielsen, L. R., E. Jørgensen, A. R. Kristensen, and S. Østergaard. 2010. Optimal replacement policies for dairy cows based on daily yield measurements. J. Dairy Sci. 93:75-92.

Østerås, O., V. L. Edge, and S. W. Martin. 1999. Determinants of success or failure in the elimination of major mastitis pathogens in selective dry cow therapy. J. Dairy Sci. 82:1221-1231.

Østergaard, S., M. G. G. Chagunda, N. C. Friggens, T. W. Bennedsgaard, and I. C. Klaas. 2005. A stochastic model simulating pathogen-specific mastitis control in a dairy herd. J. Dairy Sci. 88:4243-4257.

Perrin, R. K. 1972. Asset replacement principles. Am. J. Agric. Econ. 54:60-68.

Schukken, Y. H., G. J. Bennett, M. J. Zurakowski, H. L. Sharkey, B. J. Rauch, M. J. Thomas, B. Ceglowski, R. L. Saltman, N. Belomestnykh, and R. N. Zadoks. 2011. Randomized clinical trial to evaluate the efficacy of a 5-day ceftiofur hydrochloride intramammary treatment on nonsevere gram-negative clinical mastitis. J. Dairy Sci. 94:6203-6215.

Schukken, Y. H., J. Hertl, D. Bar, G. J. Bennett, R. N. González, B. J. Rauch, C. Santisteban, H. F. Schulte, L. Tauer, F. L. Wel- come, and Y. T. Gröhn. 2009. Effects of repeated gram-positive and gram-negative clinical mastitis episodes on milk yield loss in Holstein dairy cows. J. Dairy Sci. 92:3091-3105.

Schukken, Y. H., M. J. Zurakowski, B. J. Rauch, B. Gross, L. G. Tikofsky, and F. L. Welcome. 2013. Noninferiority trial comparing a first-generation cephalosporin with a third-generation cephalosporin in the treatment of nonsevere clinical mastitis in dairy cows. J. Dairy Sci. 96:6763-6774.

Sørensen, L. P., T. Mark, M. K. Sørensen, and S. Østergaard. 2010 Economic values and expected effect of selection index for pathogen-specific mastitis under Danish conditions. J. Dairy Sci. 93:358-369.

Wilson, D. J., B. A. Mallard, J. L. Burton, Y. H. Schukken, and Y. T. Gröhn. 2007. Milk and serum J5-specific antibody responses, milk production change, and clinical effects following intramammary Escherichia coli challenge for $\mathrm{J} 5$ vaccinate and control cows. Clin. Vaccine Immunol. 14:693-699.

Yalcin, C., and A. W. Stott. 2000. Dynamic programming to investigate financial impacts of mastitis control decisions in milk production systems. J. Dairy Res. 67:515-528. 